\title{
Formação continuada de professores universitários na rede social facebook: interagir, trocar, dialogar, compartilhar, aprender e conviver
}

University professors continued formation at the facebook socialnetwork: to interact, to share, to dialogue, to participate, to learn and to live together

Formation continue de professeurs universitaires sur le réseau social facebook: communiquer, échanger, dialoguer, partager, apprendre et vivre ensemble

\author{
Formación contínua de profesores universitarios en la red social facebook: \\ interagir, cambiar, compartir, aprender y convivir
}

Rosimeire Martins Régis dos Santos ${ }^{1}$

Ana Paula Melim ${ }^{1}$

Maria Cristina Lima Paniago ${ }^{1}$

Recebido em 20/02/2017; revisado e aprovado em 27/03/2017; aceito em 27/03/2017

DOI: http://dx.doi.org/10.20435/inter.v18i2.1502

\begin{abstract}
Resumo: O artigo discute as possibilidades de uma formação continuada de professores na rede social facebook, ocorrida em 2014, sob a organização da Pró-Reitoria de Ensino e Desenvolvimento (PROED) e do Núcleo de Apoio Pedagógico (NAP) em uma Universidade particular no Estado de Mato Grosso do Sul. É uma pesquisa qualitativa de cunho etnográfico virtual e utiliza-se dos diálogos ocorridos na rede social facebook. Os resultados apontam que os professores estabelecem laços sociais e pedagógicos a partir das interações, difundindo saberes com a produção colaborativa do conhecimento.
\end{abstract}

Palavras-chave: formação continuada; rede social facebook; aprender e compartilhar.

Abstract: The article discusses the possibilities of a teachers continued formation at the social network facebook, occurred in 2014, under the organization of the Pro-Rector of Teaching and Development (PROED) and the Nucleus of Pedagogical Support (NAP) in a Private University of Mato Grosso do Sul. It is a qualitative research of Virtual Etnographic Nature and it uses dialogues happened at the facebook social network. The results show that the teachers establish social and pedagogical links from the interactions, diffusing knowledges with the collaborative production of knowledge.

Key words: continued formation; facebook social network; learn and Share.

Résumé: L’article discute les possibilités d'une formation continue de professeurs, qui a débuté en 2014 sur le réseau social facebook, par le Département Recherche et Développement (PROED) avec le concours du Service d'Appui Pédagogique (NAP) d'une Université privée de l'État du Mato Grosso do Sul. Il s'agit d'une recherche qualitative à caractère ethnographique virtuel basée sur l'étude des dialogues échangés sur le réseau social facebook. Les résultats montrent que, grâce à ces échanges, les enseignants peuvent établir des liens sociaux et pédagogiques qui leur permettent de répandre et de partager ensemble des connaissances. Mots-clés: formation continue, réseau social facebook, apprendre etpartager.

Resúmen: El artículo discute las possibilidades de formacíon contínua de los docentes en la red social facebook, hecho em 2014 con la organizacíon de la Pró Rectória de Enseño y Desarrollo (PROED) y el Núcleo de Apoyo Pedagógico (NAP) en una universidad particular del estado de mato grosso do sul. És una búsqueda cualitativa etnográfica virtual y uyiliza los diálogos ocurridos en la red social facebook. Los resultados muestram que los professores tienem lazos sociales y pedagógicos desde las interacciones, difundindo saberes con la producción de conocimientos.

Palabras clave: formación contínua, red social facebook, aprender, compartir.

\footnotetext{
${ }^{1}$ Universidade Católica Dom Bosco (UCDB), Campo Grande, Mato Grosso do Sul, Brasil.
} 


\section{INTRODUÇÃO}

A realização deste estudo partiu de formação continuada para professores do Ensino Superior em uma Universidade Privada que propõe semestralmente acolher seus docentes com uma semana pedagógica. Organizada pela Pró-Reitoria de Ensino e Desenvolvimento (PROED) e o Núcleo de Apoio Pedagógico (NAP), a oficina, a qual é o objeto deste estudo, contou com 35 professores de diferentes áreas e com quatro professores formadores das áreas de letras e pedagogia. Ocorreu, em 2014, a oficina em foco, cujo tema foi "Comunicação, colaboração e interação das redes sociais nos espaços/tempos universitários".

O objetivo da oficina foi apresentar possibilidades que levassem professores e acadêmicos à construção conjunta de espaços de aprendizagem com a utilização de diferentes recursos de interação e colaboração mediados pelas redes sociais facebook, google plus, twitter e linkedln.

A oficina ocorreu no laboratório de informática da Universidade e suscitou conceitos e questionamentos relacionados às redes sociais: o que são ferramentas de redes sociais?; por que utilizar redes sociais na educação?, buscando permanentemente estabelecer a comunicação, colaboração e interação, por meio da exposição dialogada, utilização de vídeos, evidenciando a importância do planejamento para utilizar as redes sociais e as práticas atuais.

Na sequência, foram apresentadas algumas redes sociais (facebook, google plus, twitter e linkedIn), e exploradas algumas ferramentas e aplicativos como perfil, grupo, página, mensagens, fotos, arquivos, dialogando acerca das potencialidades desses meios.

Em dado momento da oficina, foi solicitado aos professores participantes da oficina que se centrassem no facebook e explorassem a rede social e, em trio, redigissem uma proposta de atividade docente considerando a prática educativa com uma ação que pudesse ser desenvolvida com os acadêmicos utilizando aquele ambiente.

A partir desse contexto, iniciamos nossas reflexões sobre o como as tecnologias invadem nossas vidas, e começamos a problematizar suas implicações no nosso cotidiano profissional docente. Avançando em nossas discussões, a pergunta que nos inquietava era como seria uma formação continuada de professores mediada pelo facebook. Nesse sentido, buscamos discutir a formação continuada em rede e as interações nos modos de participar, produzir e compartilhar conhecimento, problematizando os espaços e tempos que as tecnologias ocupam em nossos processos formativos de vida e profissão.

A metodologia adotada nesta pesquisa trata-se de uma abordagem de pesquisa qualitativa de cunho etnográfico virtual e, como procedimento metodológico, utilizou-se a captura dos diálogos na rede social facebook. A etnografia virtual pode observar os detalhes de como os usuários experienciam esse fenômeno e percebem os relacionamentos entre as mudanças tecnológicas e o entendimento que os sujeitos têm dessas tecnologias (HINE, 2000).

É interessante mencionar aqui, como reflexão, utilizando o termo etnografia virtual, que o pesquisador se agrupa à comunidade que está sendo pesquisada, e o campo de pesquisa é agora o texto, a imagem, o vídeo e áudio em uma tela de computador e grupo de pessoas envolvidas na rede social, no ambiente virtual.

Apresentamos excertos dos momentos virtuais, ou seja, as conversações desenvolvidas na rede social facebook, no grupo intitulado "Redes Sociais nos espaços/tempos universitários". Os depoimentos foram transcritos sem qualquer alteração, e os nomes dos professores identificados por letra são fictícios no sentido de manter o anonimato dos participantes da formação.

INTERAÇÕES, Campo Grande, MS, v. 18, n. 2, p. 13-20, abr./jun. 2017. 
No sentido de promover uma experiência de criar significações com a rede social facebook na formação continuada de um grupo de professores que discutimos as próximas seções desse artigo.

\section{PLURALIDADE DE VOZES SOBRE A FORMAÇÃO CONTINUADA NA REDE SOCIAL FACEBOOK: O INTERAGIR, TROCAR E DIALOGAR}

Quando pensamos em formação continuada, sabemos que ela não se encerra no curso de formação inicial, mas continua ao longo da carreira, no ambiente de trabalho do professor (IMBERNÓN, 2004; NÓVOA, 1995; PACHECO; FLORES, 1999).

Segundo Imbernón (2004, p. 15), "[...] a formação assume um papel que transcende o ensino que pretende uma mera atualização científica, pedagógica e didática e se transforma na possibilidade de criar espaços de participação, reflexão e formação [...]", situação que se observa no comentário expresso pela professora (B) "É muito bom começar um novo ano letivo com novos desafios... aprendendo, conhecendo, repensando... novos mecanismos e grupos de aprendizagem e descobertas digitais!!".

Nessa direção, ressaltamos que construir colaborativamente uma formação continuada de professores é aproximar-se desses professores para compreender o que eles precisam, valorizando pensamentos e construindo um ambiente de discussão, possibilitando elaborar ideias de forma coletiva a favorecer o desenvolvimento da prática pedagógica.

Tardif (2002) também analisa a formação como um meio de fazer frente às crescentes demandas de atualização profissional, uma vez que, tanto em suas bases teóricas quanto em suas consequências práticas, os conhecimentos profissionais são evolutivos e progressivos e necessitam, por conseguinte, de uma formação contínua e continuada de forma coletiva.

Dessa forma, entendemos que a formação docente é um processo contínuo, no qual o professor pode procurar caminhos de formação que problematizem suas necessidades e que permitam dialogar sobre os problemas com que se deparam no seu dia a dia. Assim, consideramos que, para discutir os avanços presentes com a chegada das tecnologias de informação e comunicação (TIC) e redes sociais no espaço escolar, demanda também ao professor explorar as diferentes possibilidades de seus usos, de suas implicações, de seus sentidos e significados, de suas apropriações

Dessa forma, compreendemos que as interações entre pares no desenvolvimento de um trabalho colaborativo entre um grupo em formação continuada na rede social facebook, podem contribuir com processos reflexivos que permitam partilhas de experiências, novas ideias e ampliação dos saberes pedagógicos. Segundo Alves e Araújo (2013, p. 5):

O Facebook é uma rede social onde cada pessoa tem um perfil, com dados pessoais, fotos, vídeos, links, comentários e compartilhamentos de textos. Os participantes desta rede social adicionam seus amigos/conhecidos e mantêm contato com eles através do símbolo curtir, de comentários, de trocas de mensagens entre si, podendo visitar outros perfis.

Por meio das redes sociais, os professores podem se expressar para além do contato presencial. Entendemos que o contato nas redes sociais pode ser fundamental na consolidação da colaboração e das ligações sociais afetivas entre os integrantes da formação continuada.

o facebook vem progressivamente ganhando destaque como um vasto campo de pesquisas nas ciências sociais e humanas, com interesse crescente em seus usos na educação (TESS, 2013). 
A evolução das TIC e redes sociais favorece a colaboração e o aprendizado em rede (SILVA, 2010). Essas TIC estão criando novas oportunidades de ensino e de aprendizagem nas quais os alunos, professores, pesquisadores conversam, trocam informações e experiências por meio de conexões nos sites de redes sociais. No sentido de avançar essa reflexão, a discussão que segue é no sentido de problematizar a formação continuada frente às redes sociais.

Consideramos pertinente destacar a concepção de rede social com esteio nas ideias de Recuero (2009, p. 69), uma rede social é sempre um conjunto de atores e suas relações. Ainda afirma a autora que redes são dinâmicas e estão sempre em transformação. Essas transformações em uma rede social são largamente influenciadas pelas interações. As pessoas estão se adaptando aos novos tempos, acessando a rede para formar novos padrões de interação e criando novas formas de sociabilidade e novas organizações sociais.

Acreditamos que as tecnologias, tal como a Internet e as redes sociais, oferecem possibilidades de transformação em nossas relações com os outros e que a conectividade que elas proporcionam é central no nosso dia a dia. Outras maneiras de estar juntos emergem nos ambientes virtuais, propiciando diferentes possibilidades de produzirmos conhecimentos que sejam pertinentes e adequados à realidade contemporânea na qual estamos inseridos. Para Santos (2015, p. 58):

Ao participar de uma rede social, podemos navegar nas informações disponíveis a qualquer momento, em qualquer lugar, aprofundar o conhecimento, trocar ideias com outros integrantes, partilhar conteúdos, explorar outras possibilidades de criar e formular problemas, articulando saberes e experiências. É nessa troca recíproca que a construção de novos significados acontece em processo de formação.

Assim, entendemos que as redes sociais proporcionam algum tipo de interação coletiva, que possibilita partilha de informações, conhecimentos, interesses.

Pensamos que a participação em redes de formação coletiva possa ser um suporte de práticas de formação baseadas na partilha e no diálogo, no sentido de problematizar implicações e possibilidades encontradas na formação e na prática docente. Esse intercâmbio de aprendizagem e prática poderá ser estabelecido e discutido por meio de redes sociais virtuais. Soares e Santos (2012, p. 306) complementam afirmando que:

Não podemos centrar a formação de professores na cibercultura apenas interagindo com os espaçostempos da escola e da universidade. Estes historicamente, principalmente na Modernidade, foram os legítimos espaços de formação e da instituição de currículos. Contudo, na contemporaneidade mostram-se incapazes sozinhos de lidar com os desafios formativos do nosso tempo. Neste sentido, temos que promover a circulação, a vivência e o habitar em outros espaços cotidianos.

Se a construção do conhecimento é contínua e se aprendemos em nossas relações sociais, nas experiências profissionais coletivas, o sistema educacional necessita conceber-se de uma nova postura, no sentido de contemplar recursos inovadores, orientando a aprendizagem colaborativa, a construção do conhecimento em rede, a troca de experiências e provocando questionamentos que permitam compreender as diversidades e riquezas existentes nos mais variados grupos constituídos nas redes sociais, como relata a Professora (A) "uma bela oportunidade para trocar ideias sobre o desafio que é trabalhar com tecnologias das redes sociais como meio para promover a formação".

Pensamos que as redes sociais virtuais na educação são um importante recurso de comunicação, interação e compartilhamento de ideias, informações e conhecimentos de forma 
colaborativa, e por estas características, tornam-se uma importante ferramenta que pode ser pesquisada e explorada potencialmente na área educacional. Segundo Soares e Almeida (2005, p. 3):

[...] uma rede virtual ou um ambiente de aprendizagem pode ser concebido de forma a romper com as práticas usuais e tradicionais de ensino- aprendizagem como transmissão e passividade do aluno e possibilitar a construção de uma cultura informatizada e um saber colaborativo, onde a interação e a comunicação são fontes da construção da aprendizagem.

Assim sendo, entendemos a importância do professor apropriar-se das tecnologias de informação e comunicação e redes sociais refletindo sobre suas possibilidades, propondo atividades e estratégias diferenciadas ao utilizar essas redes, como exemplificado nos comentários a seguir:

Estou muito feliz com o que aprendi hoje... já planejei uma aula usando isso daqui... cara é muito bom... dá para colocar textos... vídeos... fotos...links... é tudo de bom. Professor (I).

Acredito que o paradigma do ensino nas redes sociais deve ser quebrado, e hoje estamos contribuindo para isso, a mudança é complexa e dificultosa, mas é fazendo, errando e tentando que iremos atingir nosso objetivo. Professora (S).

[...] utilizo essa ferramenta como instrumento de difusão de boas ideias e boas práticas. Professora (A).

O facebook tem sido utilizado como espaço para resolução de questões que são comuns ao grupo de sala de aula, inclusive com aporte de informações de interesse de todos. Tem sido ainda utilizado como meio para organização de estudos, práticas de grupos, encontros, entre outros. É o local de encontro imediato. Professora (P).

Nós ( $\mathrm{C}$ e L) achamos viável aproveitar esse espaço no face, como um ambiente de discussão e aprendizagem [...]. Professores (C e L).

Podemos observar também que o clima descontraído, como aponta o Professor (I) "cara é muito bom... é tudo de bom", é ampliado pelas possibilidades interativas das redes. Assim, as relações afetam as comunicações realizadas na rede social repercutindo nas interações de compartilhar e aprender .

\section{OLHARES SOBRE A REDE SOCIAL FACEBOOK NA EDUCAÇÃO: O COMPARTILHAR, APRENDER E CONVIVER}

A educação aberta colaborativa em rede tem sido considerada uma filosofia educacional importante para enriquecer a aprendizagem ao longo da vida e tem proporcionado a oportunidade de aceder e de construir conhecimento através das redes sociais. O rápido crescimento dos recursos educacionais abertos (REA) na web 2.0, promovendo o acesso e uso livre de conteúdos e tecnologias, tem favorecido essa construção coletiva do conhecimento com base na reconstrução colaborativa e na redistribuição partilhada (MOREIRA; BARROS; MONTEIRO, 2014).

No grupo da rede social facebook, estabelecemos laços sociais e pedagógicos, os sujeitos comentam suas experiências, produzem e divulgam textos, imagens fotográficas, vídeos, falam alegremente como no comentário do professor (A) "Alô Professor, faço parte deste grupo. Estou dentro". A participação das pessoas que a acessam, fazendo com que seja uma participação 
colaborativa, em que o conhecimento é compartilhado coletivamente por todos é um fator motivador a aprendizagem colaborativa.

Segundo Couto (2014, p. 62), "na era das conexões, as pessoas aprendem trabalhando em conjunto, colaborando umas com as outras, com os professores e também entre si". Os comentários expressos na fala dos professores postados no facebook proporcionaram formas colaborativas de aprender, relacionadas ao prazer de compartilhar, como exemplificam à seguir:

Muito interessante. Baixei e vou estudar. Gostei até do formato, bem desenhado. E essa comunidade (a Casa da Cultura Digital) é espetacular. Professor (R).

Professor (A), gostei do comentário que você fez sobre o Baumman. Por favor me envie o texto... Professor (J). Professor (A), na sexta, quando vier para a palestra Ihe trarei o artigo.

Olá Professora (R)... bom vc nos disponibilizar material para leituras aqui... parece bem bom o livro... Grato...

Em um evento conversei com uma professora e pesquisadora que escreveu um livro relatando que superou os obstáculos de sua deficiência física a partir da inclusão digital para realizar seus objetivos. Livro: Vôo da Águia: Uma Autobiografia. Professora (R). Legal! Vou procurar! Abraço Professor (T).

Olá colegas! Eu e o professor (O), queremos compartilhar com vocês uma proposta desenvolvida por nós e outros professores dos Cursos de Jornalismo e Publicidade e Propaganda que engloba conteúdos multimídia que são compartilhados pelas redes sociais na Web. Professora (C).

Diante das conversas apresentadas entre os professores ( $\mathrm{J}$ e A), é possível perceber que a interação on-line iniciada no espaço eletrônico é capaz de desencadear repercussões no espaço físico (e vice-versa). Sobre isso, Couto Junior e Oswald (2014, p. 180) dizem que "os espaços físicos e eletrônicos são indissociáveis nos processos comunicacionais". Nesse contexto, caminham juntos com as relações sociais estabelecidas no virtual e no espaço físico da Universidade.

Também podemos observar, na fala dos professores, que a rede social permite a partilha de informações, ou seja, proporciona aos sujeitos novas formas de buscar, novas relações do sujeito com a informação. "[...] essas redes são, quase sempre, mutantes e tendem a apresentar comportamentos criativos, inesperados e emergentes" (RECUERO, 2009, p. 91-92). Ainda, pensamos que, uma vez criado o grupo no facebook, as novas conexões que fazem parte do leio, reflito, concordo, discordo, curto, comento, compartilho podem contribuir com laços afetivos e com o trabalho colaborativo indo ao encontro dos diferentes atores que fazem parte do grupo. Ou, seja:

[...] as redes sociais podem facilitar a criação de comunidades de prática ou de aprendizagem em que representam ambientes intelectuais, culturais, sociais e psicológicos que facilitem e sustentam a aprendizagem, enquanto promovem a interação, a colaboração e o desenvolvimento de um sentimento de pertença dos seus membros. (MOREIRA; JANUÁRIO, 2014, p. 74).

Assim, perceber como se pode ensinar, aprender e conviver em espaços de rede social na internet, como o facebook, é um dos desafios que se colocam aos educadores. Como observa Lévy (1999), os dispositivos digitais como mediadores de aprendizagem permitem e intensificam a partilha de informações, um aprendizado colaborativo, onde juntos alunos e professores mobilizam em comum recursos, informações, imagens, atualizando seus saberes disciplinares, pedagógicos e de formação. 


\section{CONSIDERAÇÕES}

Sabemos que as redes sociais têm contribuído e ampliado as discussões para além do ciberespaço. A formação continuada de professores pensada em redes sociais, para discutir temas específicos, tem se mostrado de forma positiva quando os seus recursos e potencialidades são utilizados de forma crítica pelos participantes. Os resultados apontam que os professores estabelecem laços sociais e pedagógicos a partir das interações na difusão de saberes com a produção colaborativa do conhecimento. A extensão das redes sociais parece apontar para processos de aprendizagem desde que exista uma intencionalidade educativa explícita. Portanto pode-se dizer que ensinar, aprender e conviver em espaços de rede social na internet, como o facebook, é um dos desafios que se colocam aos educadores.

\section{REFERÊNCIAS}

ALVES, Thelma Panerai; ARAÚJO, Renata. O Moodle e o Facebook como ambientes pedagógicos: concepções discentes acerca do uso destes ambientes. Em teia - Revista de Educação Matemática e Tecnológica Iberoamericana, Pernambuco, v. 4, n. 2, p. 16-32, 2013.

COUTO, Edvaldo Souza. Pedagogias das conexões: compartilhar conhecimentos e construir subjetividades nas redes sociais digitais. In: PORTO, Cristiane; SANTOS, Edméa (Org.). Facebook e educação: publicar, curtir, compartilhar. Campina Grande: EDUEPB, 2014. p. 47-66.

COUTO JUNIOR, Dilton Ribeiro; OSWALD, Maria Luiza. Fico sem nada de interessante pra postar qnd estou recatada!- a relação entre o espaço eletrônico e o espaço físico em conversas mantidas entre jovens no Facebook. In: PORTO, Cristiane; SANTOS, Edméa (Org.). Facebook e educação: publicar, curtir, compartilhar. Campina Grande: EDUEPB, 2014, p. 167-183.

HINE, Christine. Virtual ethnography. London: SAGE Publications, 2000.

IMBÉRNON, Francisco. Formação docente e profissional: formar-se para a mudança e a incerteza. São Paulo: Cortez, 2004

LÉVY, Pierre. Cibercultura. São Paulo: Editora 34, 1999. 264p.

MOREIRA, J. A.; BARROS, D.; MONTEIRO, A. Apresentação. In: (Org.) Educação a Distância e eLearning na web social. Santo Tirso: Wh!te Books, 2014. p. 17-22.

MOREIRA, José A.; JANUÁRIO, Susana. Redes sociais e Educação: reflexões acerca do facebook enquanto espaço de aprendizagem. In: PORTO, Cristiane; SANTOS, Edméa (Org.). Facebook e educação: publicar, curtir, compartilhar. Campina Grande: EDUEPB, 2014. p. 67-84.

NÓVOA, Antonio. Os professores e as histórias da sua vida, in: NÓVOA, A. (Org.). Vidas de Professores. Porto: Porto Editora, 1995. p. 11-30.

PACHECO José Augusto; FLORES, Maria Assunção. Formação e avaliação de professores. Porto: Porto Editora, 1999.

RECUERO, Raquel. Redes sociais na internet. Porto Alegre: Sulina, 2009.

SANTOS. Rosimeire Martins Régis. Formação continuada de professores indígenas e não indígenas: implicações e possibilidades interculturais em contexto presencial e em redes sociais. 2015. 234f. Tese (Doutorado em Educação)- Universidade Católica Dom Bosco, Campo Grande, MS, 2015.

SILVA, Marco. Educação online: cenário, formação e questões didático-metodológicas. Rio de Janeiro: Wak Ed., 2010.

SOARES, Conceição; SANTOS, Edméa. Artefatos tecnoculturais nos processos pedagógicos: usos e implicações para os currículos. In: ALVES, Nilda; Libâneo, José Carlos. Temas de Pedagogia: diálogos entre didática e currículo. São Paulo: Editora Cortez, 2012. p. 308-330.

INTERAÇÕES, Campo Grande, MS, v. 18, n. 2, p. x-xx, abr./maio 2017. 
SOARES, Eliana Maria do Sacramento; ALMEIDA, Cláudia Zamboni. Interface gráfica e mediação pedagógica em ambientes virtuais: algumas considerações, 2005. Disponível em: <http://ccet.ucs.br/pos/especializa/ ceie/ambiente/disciplinas/pge0946/material/biblioteca/sacramento_zamboni_conahpa_2005.pdf>. Acesso em: 17 jul. 2015.

TARDIF, Maurice. Saberes docentes e formação profissional. Petrópolis, RJ: Vozes, 2002.

TESS, Paul A. The role of social media in higher education classes (real and virtual) - a literature review. Computers in Human Behaviour, v. 29, p. 60-68, 2013.

Sobre as autoras:

Rosimeire Martins Régis dos Santos: Doutora em Educação. Professora de cursos de Graduação e Pós Graduação da UCDB Virtual. Integrante do Grupo de Pesquisas e Estudos em Tecnologia Educacional e Educação a Distância (GETED). E-mail: profarosimeireregis@hotmail.com

Ana Paula Melim: Pedagoga, Mestre em Educação. Coordenadora Pedagógica e Professora de cursos de Graduação e Pós Graduação da UCDB. Integrante do Grupo de Pesquisas e Estudos em Tecnologia Educacional e Educação a Distância (GETED). E-mail: anamelim@terra.com.br

Maria Cristina Lima Paniago: Doutora em Linguística Aplicada e Estudos da Linguagem pela Pontifícia Universidade Católica de São Paulo; Líder do Grupo de Pesquisas e Estudos em Tecnologia Educacional e Educação a Distância (GETED); Professora do Programa de PósGraduação em Educação Mestrado e Doutorado na Universidade Católica Dom Bosco (UCDB). E-mail: cristina@ucdb.br 